\title{
Assessing student preferences between on-site and on-line instruction during social distancing: Differences between undergraduate and graduate students
}

\author{
Drs. R. Wade Smith \& Rebecca Robichaux-Davis
}

\begin{abstract}
This article reports the results of the phase I, multisite study, assessing preferences for traditional or on-line instruction between undergraduate and graduate students. Theses students had initially enrolled in a traditional (i.e., on-site) platform of instruction but due to the national distancing policy were instead instructed via an on-line only format. A mixed-method research design was employed using an author-developed survey instrument to assess instruction preference and two open-ended questions; the answers to which were subjected to content analysis.
\end{abstract}

\section{PURPOSE OF STUDY}

This article reports the results of the phase I, multisite study, assessing preferences for traditional or on-line instruction between undergraduate and graduate students. Theses students had initially enrolled in a traditional (i.e., on-site) platform of instruction but due to the national distancing policy were instead instructed via an on-line only format. A mixed-method research design was employed using an author-developed survey instrument to assess instruction preference and two open-ended questions; the answers to which were subjected to content analysis.

\section{Participants}

The sample for this multisite study was comprised of 26 undergraduate students and 15 graduate students majoring in education enrolled in major universities located in southeastern United States. Because of the small-cell syndrome, no demographic information was collected to assure confidentiality of the respondents.

\section{Instrumentation}

The Traditional versus Online Instruction Preference Scale (TOIPS) (Smith, 2020) is a six-item bipolar summative response instrument with lower scores (1 to 3) indicating stronger preferences for traditional instruction and higher scores (5 to 7) designating greater preferences for online instruction with 4 representing no preference between the two platforms (See Appendix 1). An item analysis was conducted on the six items hypothesized to assess Instruction Preference. Each of the six items was correlated with the total score (with the item removed). All of the correlations were greater than 0.30 with a Cronbach's alpha of 0.89 indicating strong internal consistency.

Results

A one-way multivariate analysis of variance (MANOVA) was conducted to determine differences between undergraduate and graduate students on the six items of the TOIPS. Results indicated 
Smith, R. W., \& Robichaux-Davis, R. (2020). Assessing student preferences between on-site and on-line instruction during social distancing: Differences between undergraduate and graduate students. Advances in Social Sciences Research Journal, 7(5) $173-177$.

significant differences between the groups, Wilks' Lambda $=0.42, F(1,35)=10.03, p<.01$. The multivariate eta-square $=0.38$ indicates that $38 \%$ of the multivariate variance of the six survey items is associated with group (undergraduate or graduate) differences. Independent samples ttests were conducted as follow-up tests to the MANOVA. The Holms-Sequential Bonferroni technique was used to control for inflated Type I errors. Results of the t-tests reported that undergraduate students scored statistically significantly lower on all six-survey items than graduate students. Descriptive statistics are presented in the Table and Graph below.

Table 1

\begin{tabular}{|c|c|c|c|c|c|c|c|c|c|}
\hline & & \multirow{2}{*}{$\mathbf{N}$} & \multirow{2}{*}{ Mean } & \multirow{2}{*}{$\begin{array}{c}\text { Std. } \\
\text { Deviation }\end{array}$} & \multirow{2}{*}{$\begin{array}{l}\text { Std. } \\
\text { Error }\end{array}$} & \multicolumn{2}{|c|}{$\begin{array}{l}\text { 95\% Confidence Interval } \\
\text { for Mean }\end{array}$} & \multirow{2}{*}{$\underset{\mathrm{m}}{\text { Minimu }}$} & \multirow{2}{*}{$\begin{array}{c}\text { Maximu } \\
\text { m }\end{array}$} \\
\hline & & & & & & $\begin{array}{l}\text { Lower } \\
\text { Bound }\end{array}$ & $\begin{array}{l}\text { Upper } \\
\text { Bound }\end{array}$ & & \\
\hline \multirow{3}{*}{$\begin{array}{l}\text { Instructional } \\
\text { pacing }\end{array}$} & Undergrad & 26 & 2.23 & 1.818 & .357 & 1.50 & 2.97 & 1 & 7 \\
\hline & Grad & 15 & 4.47 & 1.407 & .363 & 3.69 & 5.25 & 2 & 7 \\
\hline & Total & 41 & 3.05 & 1.987 & .310 & 2.42 & 3.68 & 1 & 7 \\
\hline \multirow{3}{*}{$\begin{array}{l}\text { Interact with } \\
\text { instructor }\end{array}$} & Undergrad & 26 & 2.12 & 1.479 & .290 & 1.52 & 2.71 & 1 & 6 \\
\hline & Grad & 15 & 3.93 & 1.438 & .371 & 3.14 & 4.73 & 1 & 7 \\
\hline & Total & 41 & 2.78 & 1.696 & .265 & 2.25 & 3.32 & 1 & 7 \\
\hline \multirow{3}{*}{$\begin{array}{l}\text { Interact with } \\
\text { classmates }\end{array}$} & Undergrad & 26 & 1.42 & .987 & .194 & 1.02 & 1.82 & 1 & 4 \\
\hline & Grad & 15 & 2.53 & 1.727 & .446 & 1.58 & 3.49 & 1 & 7 \\
\hline & Total & 41 & 1.83 & 1.395 & .218 & 1.39 & 2.27 & 1 & 7 \\
\hline \multirow{3}{*}{$\begin{array}{l}\text { Completing } \\
\text { course } \\
\text { requirements }\end{array}$} & Undergrad & 26 & 2.81 & 1.960 & .384 & 2.02 & 3.60 & 1 & 7 \\
\hline & Grad & 15 & 4.07 & 1.335 & .345 & 3.33 & 4.81 & 1 & 6 \\
\hline & Total & 41 & 3.27 & 1.844 & .288 & 2.69 & 3.85 & 1 & 7 \\
\hline \multirow{3}{*}{$\begin{array}{l}\text { Quality of } \\
\text { feedback }\end{array}$} & Undergrad & 26 & 2.54 & 1.421 & .279 & 1.96 & 3.11 & 1 & 6 \\
\hline & Grad & 15 & 3.87 & 1.246 & .322 & 3.18 & 4.56 & 1 & 6 \\
\hline & Total & 41 & 3.02 & 1.491 & .233 & 2.55 & 3.50 & 1 & 6 \\
\hline \multirow{3}{*}{$\begin{array}{c}\text { Overall } \\
\text { Instructional } \\
\text { effectiveness }\end{array}$} & Undergrad & 26 & 2.08 & 1.055 & .207 & 1.65 & 2.50 & 1 & 4 \\
\hline & Grad & 15 & 3.73 & 1.580 & .408 & 2.86 & 4.61 & 1 & 7 \\
\hline & Total & 41 & 2.68 & 1.491 & .233 & 2.21 & 3.15 & 1 & 7 \\
\hline
\end{tabular}




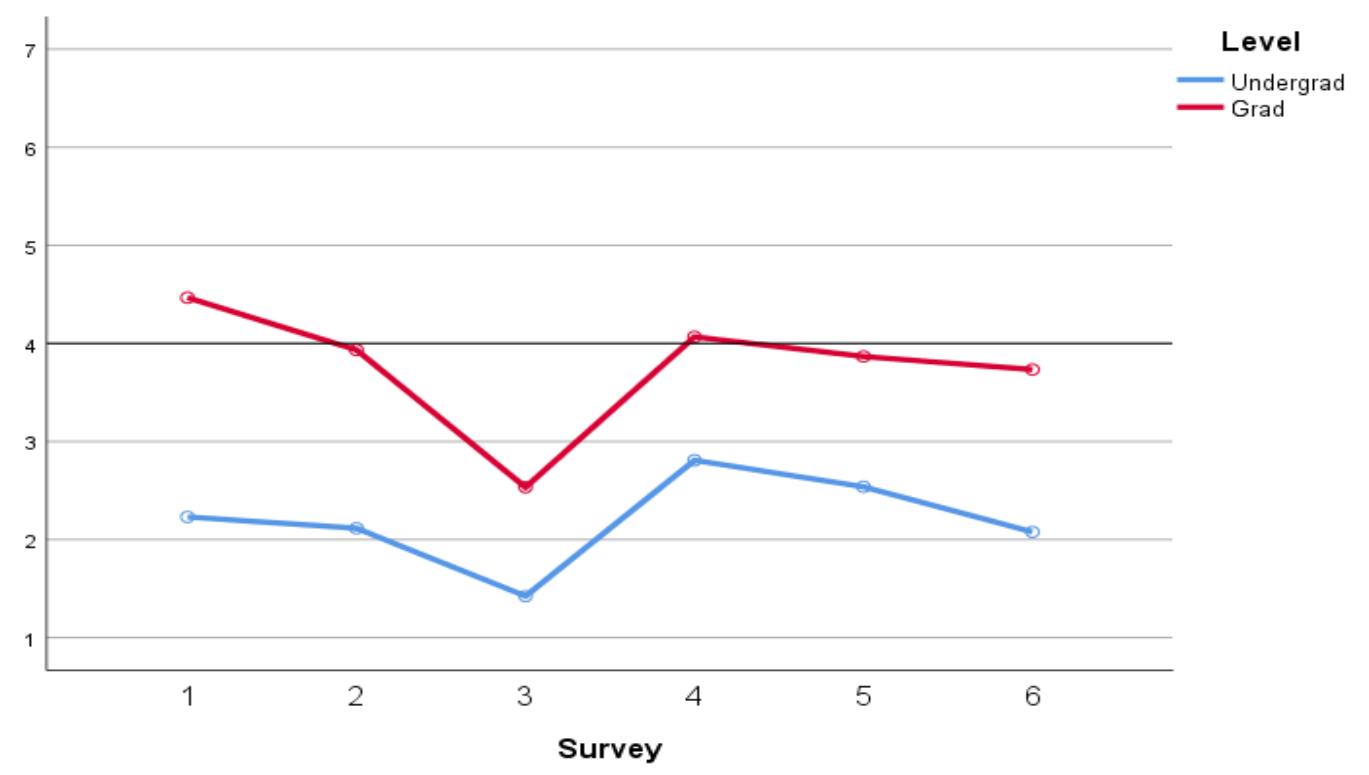

Graph 1

NB: All the undergraduate students are significantly below the y-axis 4-line (indicating no preference), whereas the graduate students indicated "no-preference" except for item 3 (Interact with classmates) indicating that graduate students prefer on-site instruction for that item.

\section{QUALITATIVE RESULTS}

The open response questions were included to provide a richer understanding of how students were perceiving their rapid transition to an online instructional platform and what they might offer as suggestions for ongoing efforts.

Although undergraduate students differed significantly from graduate students in their preference for on-site (traditional) instruction, both groups displayed a recognition that the current circumstances were beyond everyone's ability to control as well as predict. The cohorts all expressed a general appreciation for the efforts that have been made to this point by instructional staff. Importantly, given the abrupt shift from traditional to online instruction, the cohorts all provide documentation that their perception of instructional effectiveness is generally favorable.

That said, there were some important observations that should prove useful to improving instructional delivery in the event there is an enduring need. There is a general awareness from the cohorts that the ability to personally interact with their peers is mitigated by the online platform. Several comments alluded to the inability to interact with their peers in real time. Furthermore, the students ascribed a learning benefit to being able to interact in a traditional classroom. From their perspective, the conversations that can arise organically within a classroom are, for the most part, outside the reach of an online platform.

The perceived benefits of the face-to-face interactions strongly suggest a need to visit strategies that can mimic meeting in a traditional classroom manner. Being able to see everyone in the class is something that several students noted would be beneficial. Although Google Class does not provide 
Smith, R. W., \& Robichaux-Davis, R. (2020). Assessing student preferences between on-site and on-line instruction during social distancing: Differences between undergraduate and graduate students. Advances in Social Sciences Research Journal, 7(5) 173-177.

that ability, it does provide an add-on application that will place everyone on a tiled screen. This option was recently discovered for the graduate cohorts and will be in place for the remainder of the semester. Through the Cisco WebEx platform, the undergraduates were able to see each of the classmates during regular synchronous class time, although this did not seem to promote much in the way of class discussion.

Another limitation noted by both the undergraduate and graduate cohorts alike was the inability to achieve meaningful field experience hours. Concerns were voiced by the undergraduates that they were missing in-class field experiences and student teaching hours that are both critical to successfully transitioning from the classroom as a student into the classroom as a teacher. Similarly, graduate cohorts are concerned about the limitations they have experienced in terms of gaining field experience hours and activities. These concerns are understandable, and it is difficult to envision an instructional platform that is totally online providing opportunities for meaningful field experiences as long as online classes are the norm for schools $\mathrm{K}-12$ as well as colleges and universities.

Even with these limitations, quality of the online instruction was viewed as comparable to face-toface instruction. This finding is encouraging, since it would be difficult to envision student satisfaction with any platform that failed to provide the necessary knowledge and skills appropriate to the degree that is being pursued.

\section{DISCUSSION}

The comments from the program evaluations are a reason for optimism. Given the unexpected requirement to change the mode of instructional delivery with essentially no warning, it is encouraging to see the resilience displayed by all cohorts. Resilience can only go so far though, and the limitations placed upon field experiences are real and significant and no easy path is in place to rectify that limitation. In short, you cannot provide field experiences when there is no field currently in place. Still, from a holistic perspective, it is encouraging to see that, at least for these cohorts, their time has generally been productive and beneficial.

\section{APPENDIX 1 \\ Program Evaluation for Traditional vs. Online Instruction Instructions:}

Complete the following items using the seven-point rating scale provided.

1, 2, and 3 represent a preference for traditional, face-to-face instruction, with 1 representing the strongest rating.

4 represents no preference for traditional or on-line; both options are viewed equally. 5,6 , and 7 represent a preference for on-line instruction, with 7 representing the strongest rating. 
Instructional pacing

1

2

3

4

5

6

7

Ability to interact with instructor

1

2

3

4

5

6

7

Ability to interact with classmates 1

23

4

5

6

7

Completing course requirements

1

2

3

4

5

6

7

Quality of feedback

12

3

4

5

6

7

Overall Instructional effectiveness

1

2

3

4

5

6

7

How could on-line instruction better serve you?

Any other thoughts on traditional or on-line instruction 